\title{
Experimental Study on Pressure Drop and Flow Dispersion in Packed Bed of Natural Zeolite
}

\author{
Petric Marc Ruya, Herri Susanto*, and Mubiar Purwasasmita \\ Institut Teknologi Bandung, Department of Chemical Engineering, 40132 Bandung, Indonesia
}

\begin{abstract}
The use of conventional correlation for pressure drop and dispersion coefficient calculation may result in inaccurate values for zeolite packed bed as the correlations are generally developed for regularly shaped and uniformly sized particles. To support the research on the application of modified natural zeolite as tar cracking catalyst, the research on the hydrodynamic behaviour of zeolite packed bed has been conducted. Experiments were carried out using a glass column with diameter of $37.8 \mathrm{~mm}$. Natural zeolite with particle size of about 2.91 to $6.4 \mathrm{~mm}$ was applied as packing material in the column, and the bed height was varied at 9,19 and $29 \mathrm{~cm}$. Air was used as the fluid that flows through the bed and nitrogen was used as a tracer for residence time distribution determination. Air flow rates were in the range of 20 to $100 \mathrm{~mL} / \mathrm{s}$ which correspond to the laminar-transitional flow regime. The pressure drops through the bed were in the range of 1.7 to $95.6 \mathrm{~Pa}$, depending on the air flow rate and bed height. From these values, the parameters in the Ergun equation were estimated, taking into account the contribution by wall effect when the ratio of column to particle diameter is low. The viscous and inertial term constants in the Ergun equation calculated ranges from 179 to 199 and 1.41 to 1.47 respectively while the particle sphericity ranges from 0.56 to 0.59 . The reactor Peclet number were determined to range from 5.2 to 5.5 , which indicated significant deviation from a plug flow condition.
\end{abstract}

\section{Introduction}

Syngas produced through biomass gasification will generally contains tar which must be removed prior to utilization as tar may cause various problems when it condense in the downstream equipment. Catalytic tar cracking is one of the most promising method for tar removal due to the absence of subsequent waste. Gasification Group of ITB Chemical Engineering Department is currently working on the development of tar cracking catalyst through the modification of domestic natural zeolite. Natural zeolite particles are irregularly shaped and distributed in size. The pressure drop and extent of deviation from plug flow condition on the fluid that flows through the zeolite packed bed will therefore be higher compared to when more regularly shaped and uniformly sized particles are used.

The research on the zeolite particles packed bed hydrodynamic reported in this paper was conducted by initially characterizing the zeolite particles used to determine the particle diameter, roundness, sphericity and void fraction of the resulting packed bed. The measurement of pressure drop and determination of retention time distribution by tracer injection experiment were then conducted by applying the particles in a glass column. The results from the pressure drop measurement were used to estimate the equivalent particle diameter, and both the viscous and inertial term constants in the Ergun equation. The results from the tracer injection experiment were used to calculate for the reactor Peclet number. The reactor Peclet number was subsequently used to predict the effect of dispersion on the reactor performance using the kinetic data of several tar cracking catalyst tabulated by [1]. More details on the particle characterization, pressure drop measurement and tracer injection experiment can be found in the previous work [13].

\footnotetext{
Corresponding author: herri@che.itb.ac.id
} 


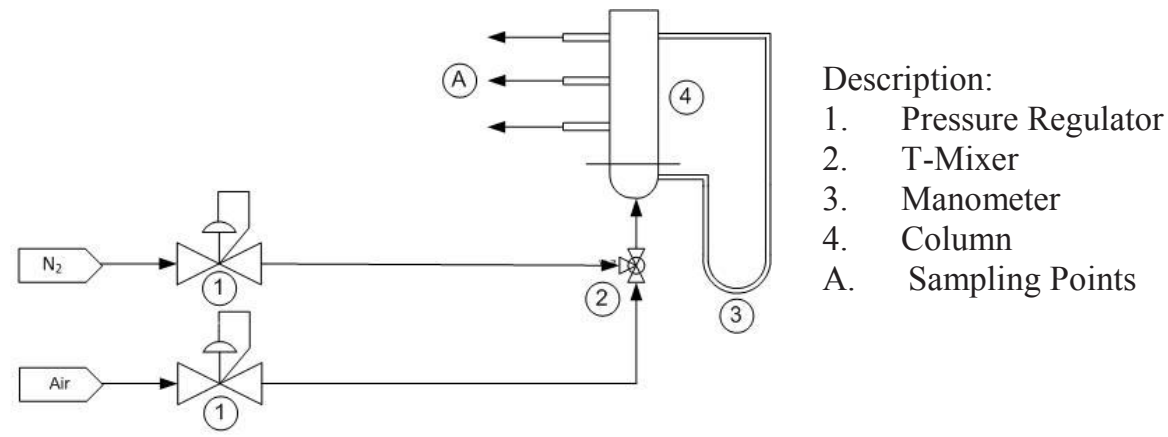

Fig. 1. Experimental set up for pressure drop measurement and tracer injection

Pressure drop measurement results were also used to calculate for the friction factor $(\mathrm{f} / 2)$, which in turn will be used to calculate for the Le Goff number. Le Goff number is the ratio of the Chilton-Colburn $\mathrm{j}$-factor to the friction factor $(\mathrm{f} / 2)$. The Le Goff number is defined by [8] to be the amount of mass or heat (energy) transported per unit amount of momentum transferred. The calculation of Le Goff number may enable the comparison of mass or heat (energy) to momentum transport efficiencies at different operating condition and thus assist in determining the most suitable operating condition. According to [15], maximum value of Le Goff number generally exists and the maximum value can be determined when the Le Goff number is plotted as a function of Reynold number. The Chilton-Colburn jfactor used in the calculation was obtained from the work of [2].

\section{Materials and Method:}

The three types zeolite particles used in the experiment were acquired from domestic sources. The first and second type originated from Sukabumi (West Java) and will be referred to as Zeolite 1A (Z1A) and Zeolite 1B (Z1B) respectively to distinguish the two from Zeolite 2 (Z2) that originates from Klaten (Central Java). Zeolite 1A has been modified for tar cracking purpose prior to the experiment.

The zeolite particles used were initially characterized to determine various parameters, such as equivalent particle diameter, particle roundness, sphericity and void fraction, when the particles were applied in packed column. Particle roundness were measured using the method described by [7].

\subsection{Equipment Set Up}

The zeolite particles were initially placed inside a cylindrical glass column with inner diameter and height of $3.78 \mathrm{~cm}$ and $50 \mathrm{~cm}$ respectively. Manometer was integrated with the column for pressure drop measurement as shown in Figure 1. The height of the zeolite packed bed was varied at 9, 19 and $29 \mathrm{~cm}$ for pressure drop measurement. Air was blown through the packed bed with the use of air compressor. Tracer injection experiment was performed on the zeolite packed bed by introducing technical grade $\mathrm{N}_{2}$ into the column. The response from the disturbance was then measured and recorded using Bacharach PCA-3 combustion analyser at every $1 \mathrm{~s}$ interval.

\subsection{Parameter Estimation}

The Ergun equation, a semi empirical model, was initially developed to be used for packed bed with uniformly sized and regularly shaped particles. The values of viscous and inertial terms constants that are generally used are 150 and 1.75 respectively. These values were developed for spherical particles. The increase in pressure drop when non-spherical particles are used as packing material can be taken into account by the inclusion of particle sphericity as shown in Equation 1.

$$
\begin{gathered}
\Delta P=150 \frac{(1-\varepsilon)^{2}}{\phi^{2} d_{p}^{2} \varepsilon^{3}} \mu u_{s} L+1.75 \frac{(1-\varepsilon)}{\phi d_{p} \varepsilon^{3}} \rho u_{s}^{2} L \\
d_{p}=\frac{6}{a_{v}} \\
a_{v}=\frac{s_{p}}{V_{p}}
\end{gathered}
$$

The particle sphericity was obtained through both volumetric measurement and parameter estimation by using the result obtained from pressure drop measurement. The definition of sphericity that is generally used in this context is the ratio of surface area of sphere with the same volume as the particle to the surface area of the particle. However, due to the difficulty in measuring the specific surface area of the zeolite particle, the particle sphericity was instead determined by initially measuring the longest side of several particles and then by measuring the average volume of a particle through water displacement method. The particle sphericity was then calculated as the cube root of the ratio of particle volume to the volume of the circumscribing sphere whereby the average longest side of the particles was taken as the diameter of the circumscribing sphere.

Parameter estimation was not only conducted to calculate for the sphericity but also for both the viscous and inertial term constants of the Ergun equation. The constants were estimated by initially assuming reliable volumetrically measured sphericity and then by allowing the particle sphericity to vary with the constants. The Ergun equation constants are not only affected by the 
particle shape; the column diameter and the particle size distribution also play significant role. The lower the ratio of column diameter to the particle diameter are, the more significant the wall effect would be. In addition, packed bed that is made using particle with larger particle size distribution will also inflict higher pressure drop on the fluid, despite having the same mean particle diameter [12]. Another approach in the parameter estimation method was also conducted where both the viscous and inertial term constants were taken as a function of equivalent particle diameter. The equivalent particle diameter, in this case, is taken as the product of sphericity with volume-mean diameter. The definition of volume mean diameter was presented by [10] and is shown in Equation 4. Volume-mean diameter can be determined by conducting only volumetric measurement.

$$
d_{v s}=\frac{6 V_{p}}{A_{s p}}
$$

The equation to calculate for both the viscous and inertial term constants were obtained from the work of [3] and is presented as Equations 5 and 6 respectively.

$$
\begin{gathered}
C_{1}=K_{1} A_{w}^{2} \\
C_{2}=\frac{A_{w}}{B_{w}} \\
A_{w}=1+\frac{2}{3\left(D / d_{p}\right)(1-\varepsilon)} \\
B_{w}=\left[k_{1}\left(\frac{d_{p}}{D}\right)^{2}+k_{2}\right]^{2}
\end{gathered}
$$

The value of the coefficients used are for the spherical particles, whereby $\mathrm{K}_{1}=154, \mathrm{k}_{1}=1.15$ and $\mathrm{k}_{2}=$ 0.87. The parameter estimation method varies the particle sphericity to calculate for the equivalent particle diameter, viscous and inertial terms constants.

\subsection{Fluid Dispersion}

The result from the tracer injection experiment was initially used to calculate for the residence time distribution with the results subsequently used to calculate for the variance and mean residence time. The reactor Peclet number was then calculated assuming open-open boundary condition. The reactor Peclet number was then used to calculate for the dispersion coefficient to be used in the axial dispersion model (Eq. 9). Using the calculated reactor Peclet number, tar cracking simulation was performed using the kinetic data tabulated by [1]. The reactor operating temperature of 600 and $700^{\circ} \mathrm{C}$ was used and toluene was used as the tar model compound in the simulation. The reactor performance simulation was performed on FlexPDE.

$$
u \frac{d C_{A}}{d z}-D_{a} \frac{d^{2} C_{A}}{d z^{2}}=r_{A}\left(\rho_{b}\right)
$$

\subsection{Calculation of Le Goff Number}

The calculation of Le Goff number requires both the friction factor ( $f / 2)$ and Chiton-Colburn $j$-factor. The results obtained from the pressure drop measurement were used to calculate for the friction factor by using Equations 10 [14] and the j-factor was calculated using the equation presented by [2] which is presented as Equations 11 and 12 respectively.

$$
\begin{array}{r}
f=\frac{1}{4}\left(\frac{D_{p}}{L}\right)\left(\frac{P_{0}-P_{L}}{0.5 \rho v_{0}^{2}}\right) \\
j=\frac{2.06}{\operatorname{Re}^{0.575} \varepsilon} \\
\operatorname{Re}=\frac{\rho u d_{p}}{\mu}
\end{array}
$$

Table 1. Toluene cracking kinetic parameter, [1]

\begin{tabular}{|c|l|c|c|c|c|}
\hline No. & \multicolumn{1}{|c|}{ Parameter } & $\begin{array}{c}\text { Ardy et al. } \\
(2015)\end{array}$ & $\begin{array}{c}\text { Palma } \\
(2013)\end{array}$ & $\begin{array}{c}\text { Agustina } \\
(2011)\end{array}$ & $\begin{array}{c}\text { Swierczynski et al. } \\
(2008)\end{array}$ \\
\hline 1. & Catalyst type & $\mathrm{Ni} / \mathrm{a}-\mathrm{Al} 2 \mathrm{O} 3$ & $\mathrm{Ni} / \mathrm{Al} 2 \mathrm{O} 3$ & Dolomite & $\mathrm{Ni} /$ Olivine \\
\hline 2. & $\begin{array}{l}\text { Frequency factor }\left(\mathrm{k}_{0}\right), \\
\mathrm{m}^{3} /\left(\mathrm{kg}_{\text {cat }} \cdot \mathrm{h}\right)\end{array}$ & 272 & 23000 & 35 & $3.14 \times 10^{13}$ \\
\hline 3. & $\begin{array}{l}\text { Activation energy }\left(\mathrm{E}_{\mathrm{a}}\right), \\
\mathrm{kJ} / \mathrm{mol}\end{array}$ & 11.6 & 40 & 13.2 & 196 \\
\hline 4. & $\begin{array}{l}\text { Toluene concentration, } \\
\mathrm{g} / \mathrm{m}^{3}\end{array}$ & 51 & 2 & $3-4$ & 27 \\
\hline 5. & Particle size $\mathrm{mm}$ & 2 & - & 1 & $0.125-0.6$ \\
\hline 6. & Bulk density, $\mathrm{kg} / \mathrm{m}^{3}$ & 939 & 939 & 2900 & 1462 \\
\hline 7. & $\begin{array}{l}\text { Catalyst requirement, } \\
\mathrm{kg} /\left(\text { mol. }^{-1}\right)\end{array}$ & 1.167 & 0.657 & 4.928 & 0.082 \\
\hline
\end{tabular}


Table 2. Comparison of parameter estimation results

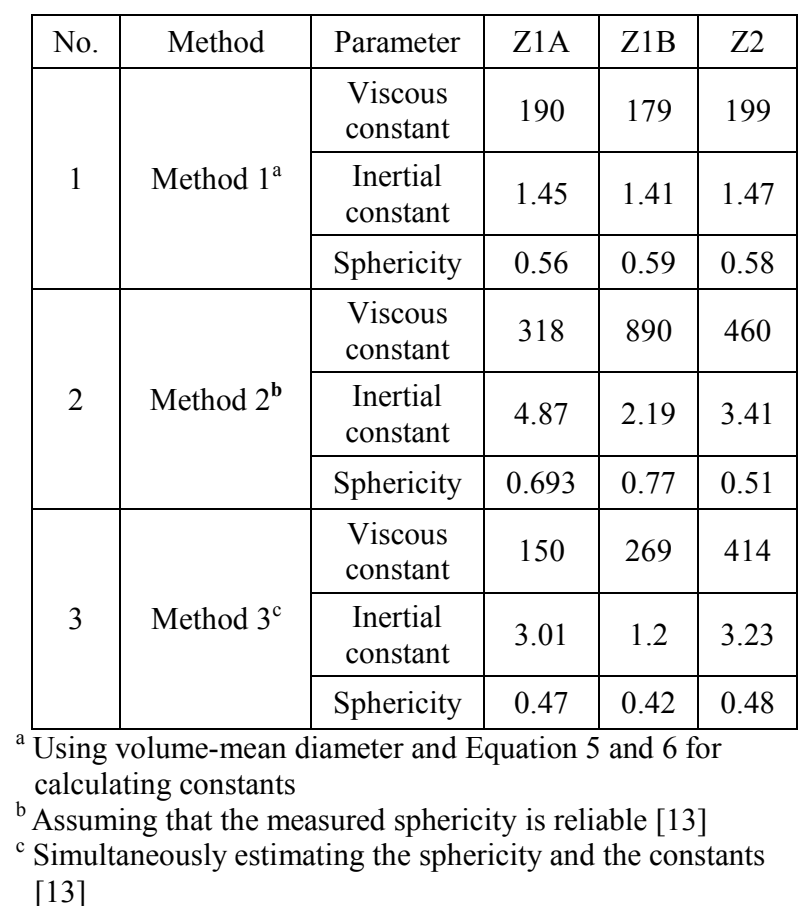

\section{Results and Discussions}

This section presents the results obtained from parameter estimation, reactor simulation and Le Goff number calculation. Details on the results obtained from particle characterization, pressure drop measurement and tracer injection experiment have been presented and discussed in the previous work [13].

\subsection{Parameter Estimation}

The results from the parameter estimation using the method that involves the use of volume mean diameter, and Equation 5 and 6 to calculate for the Ergun equation constants is presented in Table 2 along with other methods, presented and discussed in the previous work [13], for comparison.

As can be observed in Table 2, using Method 1 results in Ergun equation constants and sphericity that is relatively closer in value for every type of zeolite particles used. This method takes into account the contribution by wall effect into the Ergun equation constants and varies only sphericity to produce subsequent variation in both the equivalent particle diameter and the Ergun equation constants. The results obtained from this method suggest that the particle sphericity may be relatively similar for each zeolite type and the differences produced when the other methods were applied occurs mainly because of the wall effect and the error in measuring the equivalent particle diameter. The measurement of volume-mean diameter provides an upper limit to the equivalent particle diameter.

\subsection{Fluid Dispersion}

The reactor Peclet number obtained from the tracer injection experiment has been reported in the previous work [13]. The values of the reactor Peclet number calculated varies at about 5 for the 3 types of zeolite particles, which implies significant deviation from plug flow condition [6]. The results of the simulation is presented as Figure 2 and 3, where PF correspond to the plug flow condition and DF to dispersed flow condition. From the results of the simulation, it can be observed that lower operating temperature would cause lower catalyst activity and thus longer residence time requirement to achieve the same amount of conversion. Longer residence time thus causes the effect of fluid dispersion on the conversion to be more significant. From both Figure 2 and 3, it can be seen that the assumption of plug flow condition may cause significant overestimation of the reactor performance and this can be detrimental, especially when the very low tar content is required for subsequent use of the product gas.

Table 3. Particle Diameter

\begin{tabular}{|c|c|c|c|c|}
\hline \multirow{2}{*}{ No. } & Parameter & \multicolumn{3}{|c|}{ Value (mm) } \\
\cline { 3 - 5 } & Z1A & Z1B & Z2 \\
\hline 1 & $\begin{array}{c}\text { Volume-mean } \\
\text { diameter }\end{array}$ & 5.07 & 3.77 & 6.00 \\
\hline 2 & $\begin{array}{c}\text { Equivalent diameter } \\
\text { (estimation) }\end{array}$ & 2.82 & 2.20 & 3.51 \\
\hline 3 & $\begin{array}{c}\text { Equivalent diameter } \\
\text { (measurement) }\end{array}$ & $3.50^{\mathrm{a}}$ & 2.91 & 6.40 \\
\hline
\end{tabular}

${ }^{a}$ Averaged according to mass fraction

${ }^{\mathrm{b}}$ Volume mean diameter multiplied by sphericity 


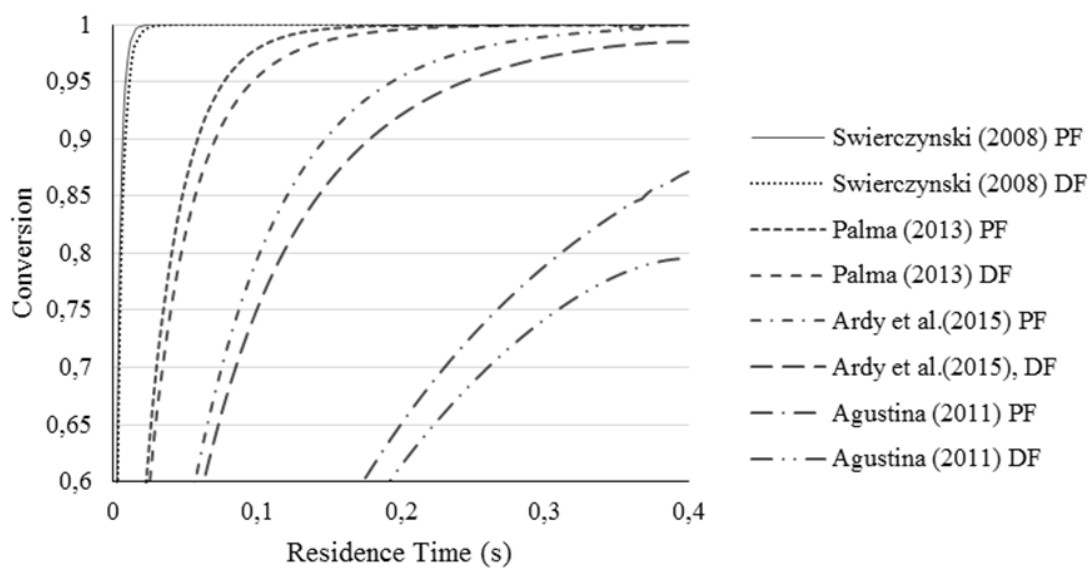

Fig. 2. Tar cracking simulation at operating temperature of $700^{\circ} \mathrm{C}$ *PF-Plug Flow, DF- Dispersed Flow

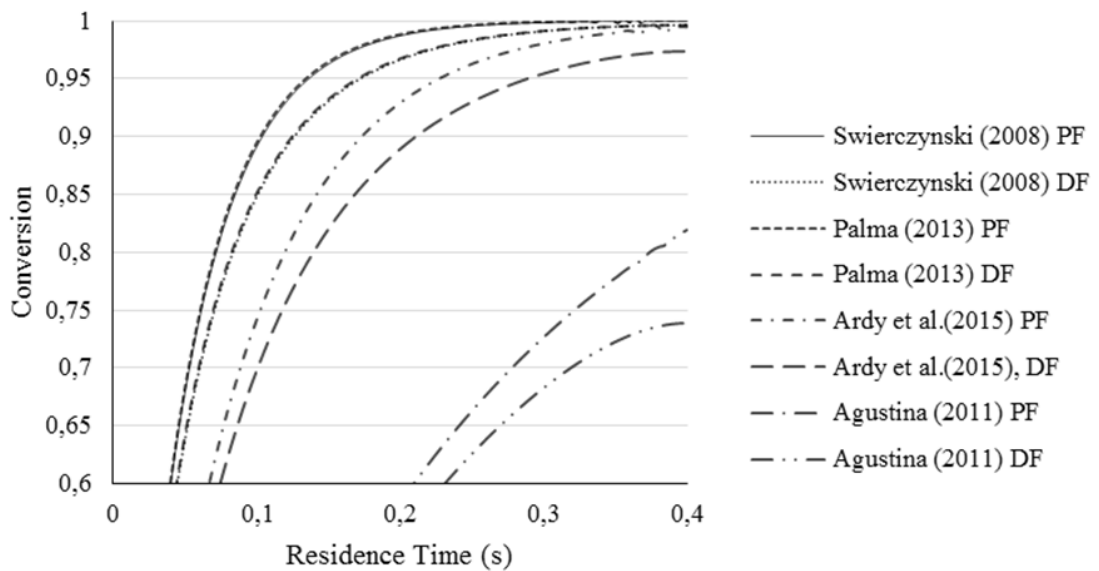

Fig. 3. Tar cracking simulation at operating temperature of $600^{\circ \mathrm{C}}$ *PF-Plug Flow, DF- Dispersed Flow

\subsection{Le Goff Number}

The plots of the Le Goff number for the three types of zeolite packed bed are shown in Figure 4. From Figure 4, the increasing trend of Le Goff number for Z1B and Z2 packed bed can be observed and this indicates that the potential for increased efficiency for mass or energy transferred per unit of momentum transferred.

The Le Goff number for Z1B produces the least scatter from the trend line and this may be attributed to the comparatively uniform particle size. As for Z1A packed bed, the graph has shown maximum point and thus the point of maximum efficiency might have been reached. However, Z1A consist of particles with the widest particle size distribution among the three types of zeolite particles and thus the peak may possibly be caused by the variation in particle size instead. The equation to calculate for the Chilton Colburn $\mathrm{j}$-factor reported by [2] were originally developed for spherical particles and thus the use of this equation for zeolite particles may results in inaccuracies.
The currently reported work deals with hydrodynamic study on zeolite packed bed under low Reynold number operating condition. Further work on higher Reynold number region should be done to determine suitable operating condition and to extend the findings to be applicable at higher Reynold number condition which is prevalent in industrial application.

The reactor Peclet number can also be used in the future work to correct the calculation of mass transfer coefficient, which generally assumes the existence of strictly plug flow condition throughout the crosssectional area of the packed bed. [9] has applied the axial dispersion coefficient in calculating the mass transfer factor (Chiton Colburn $\mathrm{j}$-factor) and reported that the previously different value obtained between packed bed and dispersed bed were very similar when corrected. 


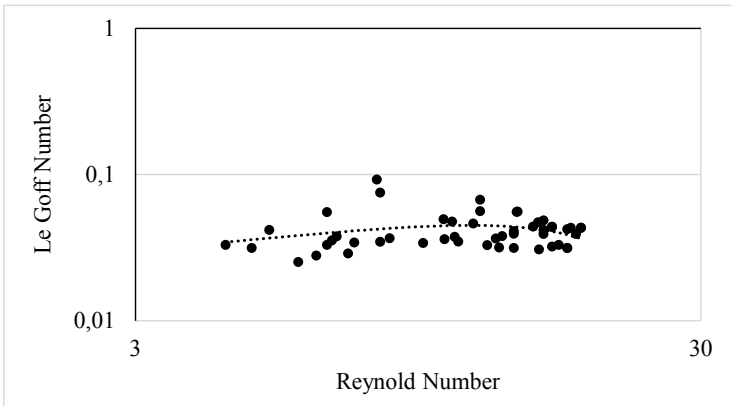

(a) Zeolite $1 \mathrm{~A}$

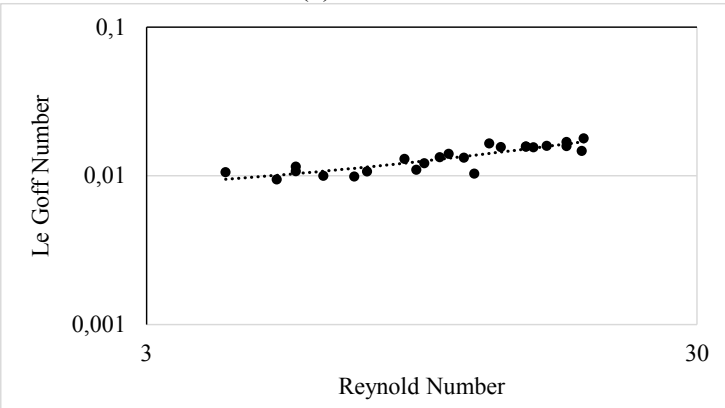

(b) Zeolite 1B

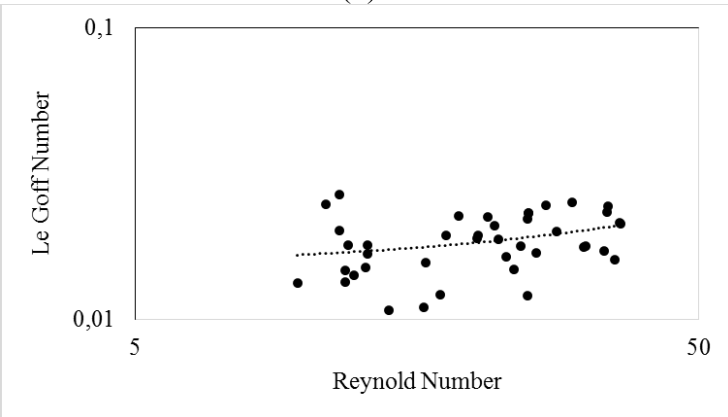

(c) Zeolite 2

Fig. 4. Plot of Le Goff number

\section{Conclusions}

Parameter estimation to determine particle sphericity and Ergun equation constants was conducted using the data obtained from pressure drop measurement. Different values of particle sphericity and Ergun equation constants were obtained when different assumption and methods were applied. Among the methods mentioned, the method which varies particle sphericity to calculate for the equivalent particle diameter and subsequently the Ergun equation constants produce relatively the most similar value of sphericity and Ergun equation constant. This may indicates the relatively substantial contribution of wall effect and equivalent particle diameter on the parameter estimation. The mentioned method takes into account the contribution by wall effect and further improvement may be obtained if the effect due to particle size distribution is also taken into account.

The reactor Peclet number indicates large amount of deviation from plug flow condition for fluid that flows through the zeolite packed bed. The result of the tar cracking simulation has revealed that the performance of the packed bed reactor may be significantly affected by the fluid dispersion. The effect becomes more significant at lower temperature as longer residence time may be required to achieve a particular amount of conversion.

The calculation of Le Goff number has revealed that the relative efficiency of heat and mass transfer per unit of momentum transferred potentially may still increase at higher Reynold number condition.

More accurate insight might be obtained if the mass or heat transfer experiment were conducted to obtain data applicable for Chilton-Colburn $\mathrm{j}$-factor calculation. The current work on fluid dispersion can also be used in future work to investigate the heat and mass transfer as this will allow the axial mixing factor to be calculated and used to correct the assumption of plug flow condition in calculating the heat or mass transfer coefficient.

This experimental study is a part of the research on the production of bio-synthesis gas and DME synthesis which are funded by Oil Palm Plantation Funds - BPDPKS, Indonesia

\section{Nomenclature}

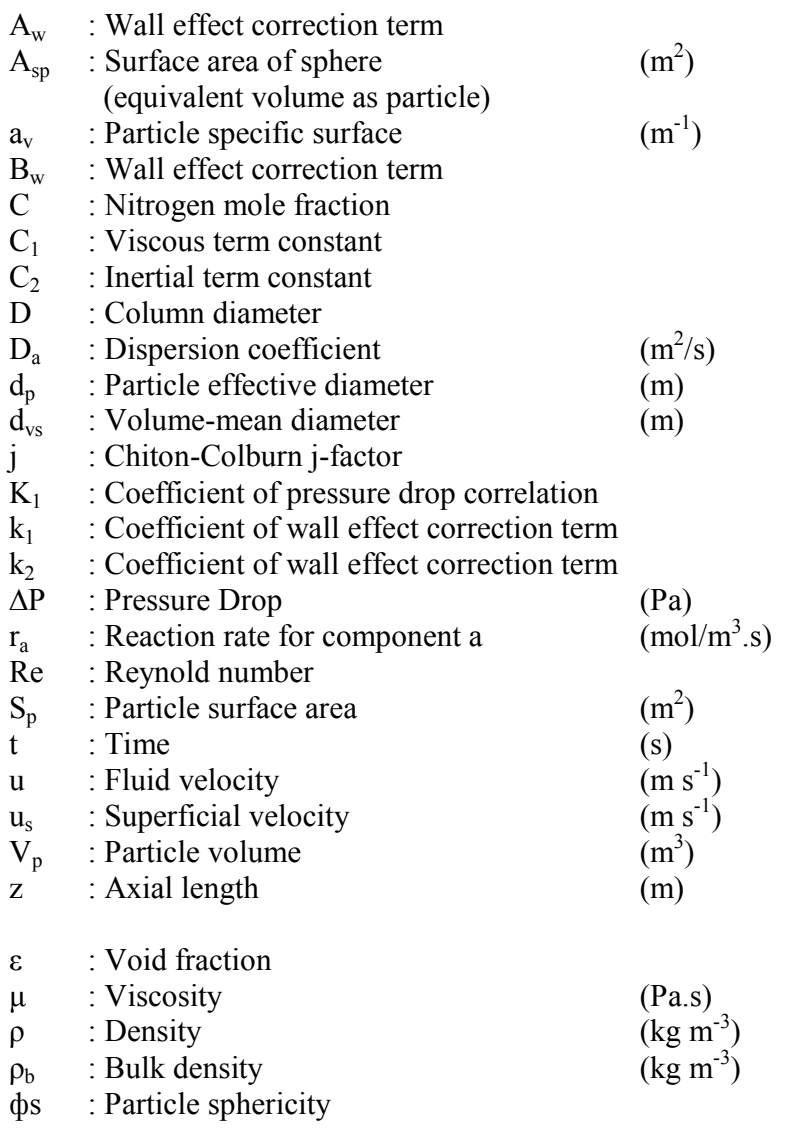

\section{References}

1. A. Ardy, Proceeding of National Chemical Engineering Seminar “Kejuangan” (Yogyakarta, 2015)

2. A.S. Gupta, G. Thodos, A.I.Ch.E. Journal , 9, 6, $751-754$ (1963) 
3. B. Eisfeld, K. Schnitzlein, Chem. Eng. Sci., 56, 14, 4321-4329 (2001)

4. C. Palma, Appl. Energy, 111, 129-141 (2013)

5. D. Swierczynski, C. Courson, A. Kiennemann, Chem. Eng. Process., 47, 3, 508-513 (2008)

6. H.S. Fogler, Elements of Chemical Reaction Engineering $4^{\text {th }}$ Edition (Prentice Hall, USA, 2006)

7. H. Wadell, J. Geol., 43, 250-280 (1935)

8. J.M. Engasser, C. Horvath, Ind. Eng. Chem, Fundamen., 14, 2, 107-110 (1975)

9. L.J. Petrovic, G. Thodos , Ind. Eng. Chem. Res., 7, 2, 274-280 (1968)

10. L. Li, W. Ma, Transport Porous Med, 89, 35-48 (2011)

11. M. Agustina, Perbandingan uji aktivitas katalis dolomit dan batu kapur lokal dengan katalis nikel komersial untuk dekomposisi toluen sebagai model konversi tar, Master's Thesis (Institut Teknologi Bandung, Bandung, 2011)

12. M.J. Keyser, M. Coradie, M. Coertzen, J.C. Van Dyk, Fuel, 85, 1439-1445 (2006)

13. P.M. Ruya, J. Waluyo, Yuono, H. Susanto, Journal of Engineering and Technological Science (in review, pending publication)

14. R.B. Bird, W.E. Stewart, E.N. Lightfoot, Transport Phenomena $2^{\text {nd }}$ edition (John Wiley \& Sons, Inc., USA, 2002)

15. M. Purwasasmita, Analogi peristiwa perpindahan massa, panas dan gerak di dalam alat-alat perpindahan dan reaktor heterogen (Institut Teknologi Bandung, Bandung, 1985) (Unpublished) 